\title{
Pacemaker implantation after transcatheter aortic valve: why is this still happening?
}

\author{
Stefan Toggweiler, Richard Kobza \\ Heart Center Lucerne, Luzerner Kantonsspital, Lucerne, Switzerland \\ Contributions: (I) Conception and design: All authors; (II) Administrative support: All authors; (III) Provision of study materials or patients: All \\ authors; (IV) Collection and assembly of data: All authors; (V) Data analysis and interpretation: All authors; (VI) Manuscript writing: All authors; (VII) \\ Final approval of manuscript: All authors. \\ Correspondence to: Dr. Stefan Toggweiler, MD. Heart Center Lucerne, Cardiology, Spitalstrasse, 6000 Luzern, Switzerland. Email: stefan.toggweiler@luks.ch.
}

\begin{abstract}
During the past years, the industry and most transcatheter aortic valve operators have focused on reduction of paravalvular leaks rather than on the reduction of permanent pacemakers (PPM). However, since indication for transcatheter aortic valve implantation (TAVI) is moving toward a healthier and younger patient population, new PPMs may become more of an issue. Certain factors such as pre-existing conduction disorders or anatomical features cannot be changed. However, the amount of mechanical trauma to the conduction system and periprocedural medical management offers the potential for optimization. By optimizing our procedure, we may finally be able to achieve low, surgical-like, PPM rates.
\end{abstract}

Keywords: Aortic stenosis; atrio-ventricular block; conduction disorder; permanent pacemaker (PPM)

Submitted Jun 11, 2018. Accepted for publication Jun 19, 2018.

doi: $10.21037 /$ jtd.2018.06.103

View this article at: http://dx.doi.org/10.21037/jtd.2018.06.103

\section{Introduction}

Transcatheter aortic valve implantation (TAVI) has been successfully performed in inoperable, high-risk, and intermediate risk patients with low mortality and complication rates $(1,2)$. Trials examining the efficacy and safety of TAVI in low-risk patients are currently enrolling patients.

While newer balloon-expandable and self-expanding TAVI devices now feature sealing skirts and are repositionable and retrievable, no specific feature has been implemented to reduce the occurrence of new conduction disorders (3). Indeed, the need for a new PPM remains a matter of concern because of its high frequency, its potential negative impact on outcomes, and its association with prolonged hospital stay and costs $(3,4)$. Long-term right ventricular pacing has been linked to electromechanical asynchrony, negative left-ventricular remodeling, increased risk for atrial fibrillation, and heart failure $(5,6)$. In light of this evidence, we should put our efforts in reducing new PPM after TAVI, particularly in an era when the indication for TAVI may expand toward treating lower-risk patients (7).

\section{Why is this still happening?}

During the past years, the focus of both TAVI operators and the industry has been more on reduction of PVL rather than on the reduction of PPM (Figure 1) $(18,19)$. For example, the reported PPM rates with the SAPIEN 3 valve (Edwards Lifesciences, Irvine, CA, USA) are more than double the rates reported with previous generation SAPIEN and SAPIEN XT valves $(8,20,21)$. The main reason for putting the focus on PVL rather than on new PPM may have come from the literature. Even in early trials, it became clear that more than mild PVL was associated with reduced survival $(22,23)$. On the other hand, the prognostic impact of new PPM after TAVI remained controversial (24). Indeed, implantation of a new PPM has been associated with reduced survival in some studies $(25)$, but not all $(24,26,27)$. A metaanalysis has even found a trend toward a protective effect from cardiac death in the first year after the 


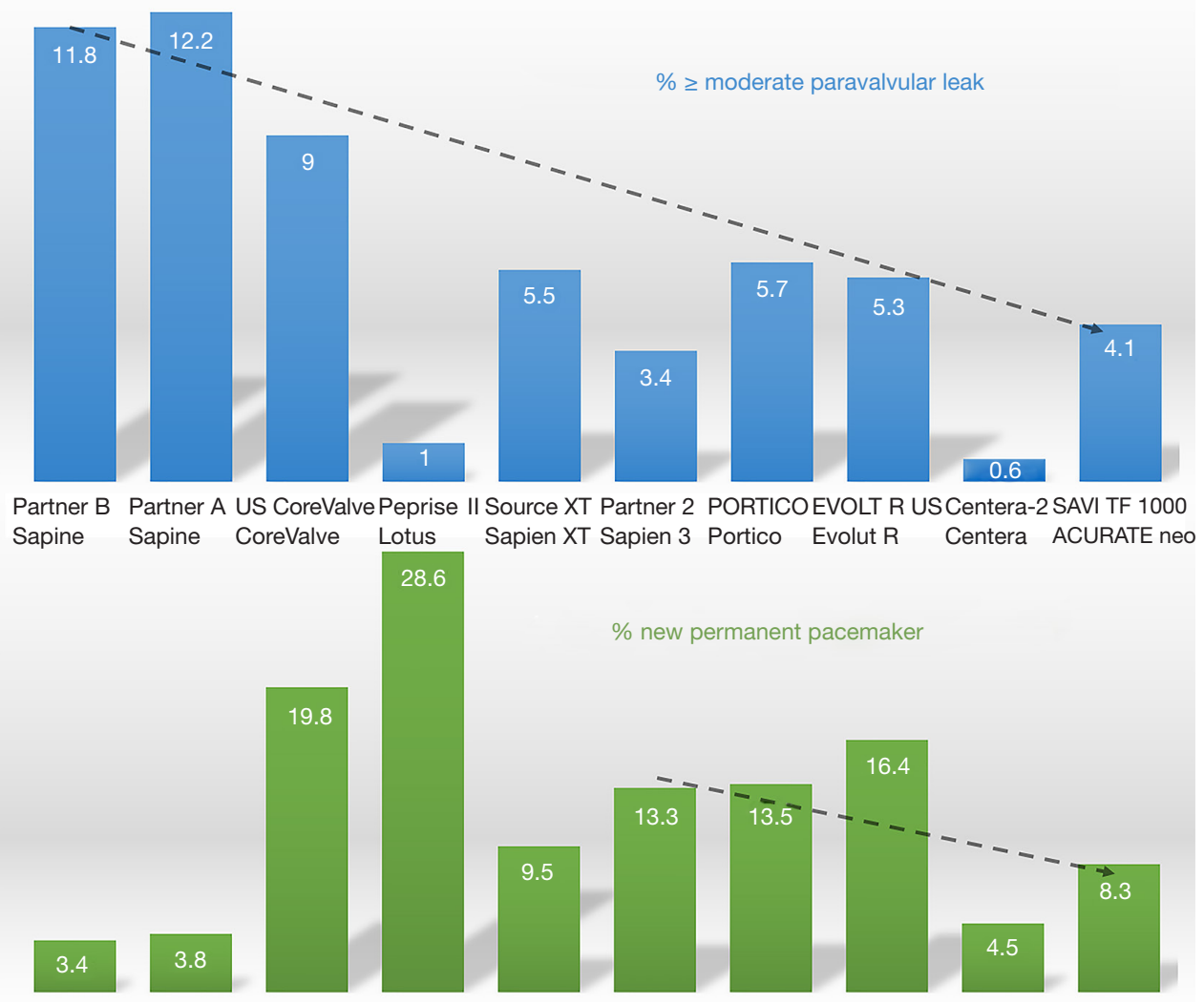

Figure 1 Evolution of paravalvular leak and need for a new permanent pacemaker after TAVI over time. Between 2011 and 2018 , there was a clear trend towards reduced rates of paravalvular regurgitation. However, after the publication of PARTNER 1B and 1A, the rate of new permanent pacemakers remained high. Only some recently published registries finally yielded lower rates of new permanent pacemakers (8-17).

procedure (24). One possible explanation for this finding may be that implantation of a PPM may protect patients with conduction disorders from potential progression towards complete AVB $(24,28)$. For instance, Auffret et al. recorded a pre-existing right bundle branch block (RBBB) in about $10 \%$ of TAVI recipients. Patients with an RBBB without a PPM at hospital discharge may be at especially high risk for high-degree AVB and sudden cardiac death during follow-up (29). Furthermore, evidence indicates that, similar to patients undergoing SAVR, about $50 \%$ of acquired conduction disorders after TAVI may resolve over time, and not all patients receiving a PPM may actually be paced during follow-up $(30,31)$. However, it is clear that a low rate of conduction disorders, particularly LBBB and first degree AVB, and a low rate of new PPM facilitates in-hospital patient management, reduces the duration of in-hospital stay, costs, and might improve long-term prognosis (32).

\section{Predictors of new conduction disorders}

Several predictors for the need of a permanent pacemaker (PPM) have been identified. Some of them, such as a preexisting $\mathrm{RBBB}$, anatomical variability, the amount and distribution of calcification or LVOT stiffness, cannot be influenced by the TAVI operator $(7,33)$. However, there are two main factors that offer the potential for optimization: the amount of trauma caused to the conduction system, and periprocedural management of medical therapy interacting with AV conduction (Figure 2).

\section{Trauma to the conduction system}

Parts of the conduction system, in particular the bundle of His and the left bundle branch, are located in immediate vicinity to the base of the non-coronary and rightcoronary leaflets. This vicinity explains the occurrence of periprocedural conduction disorders. Electrophysiological 


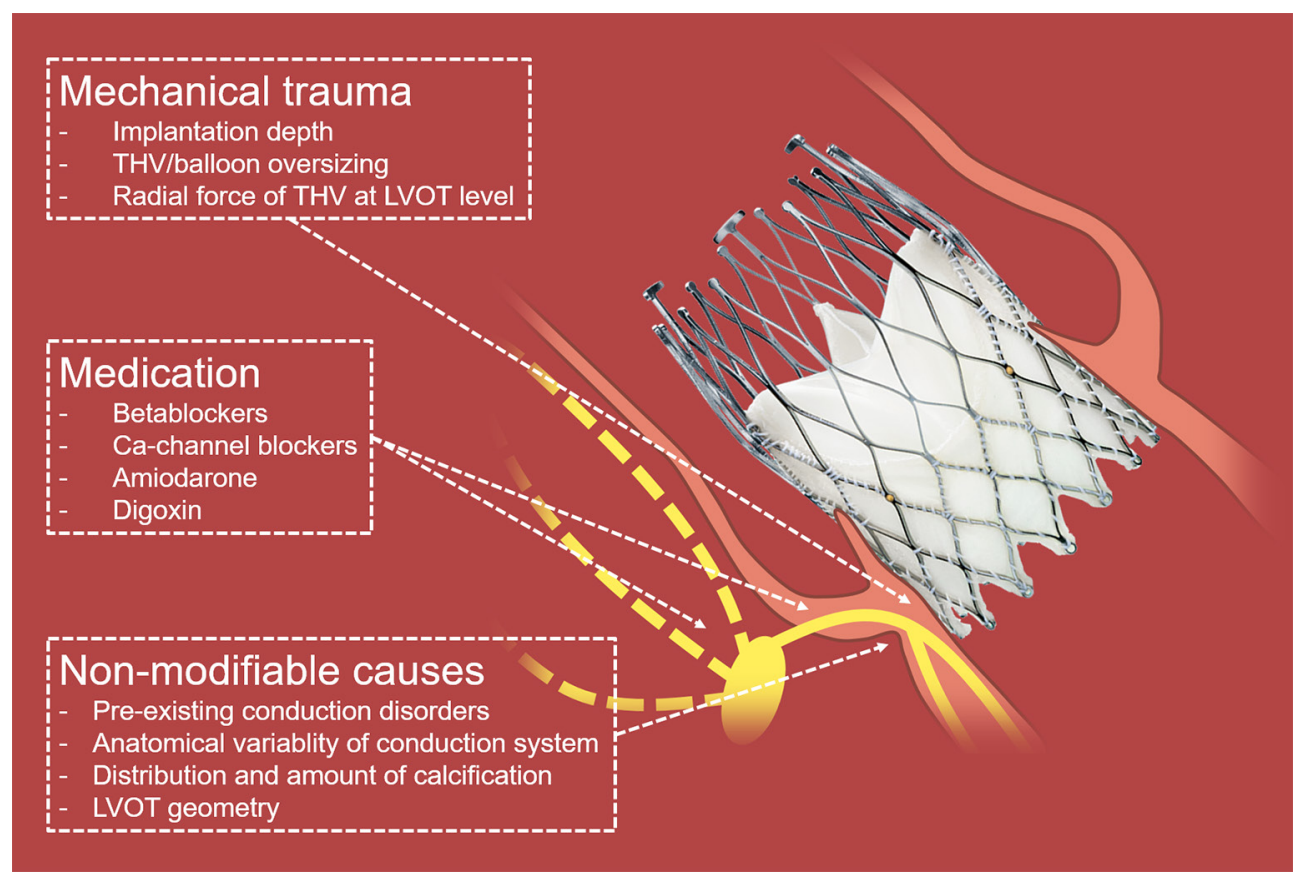

Figure 2 Modifiable and non-modifiable causes for conduction disorders after TAVI. Some causes and risk factors such as pre-existing conduction abnormalities are non-modifiable, but some can potentially be influenced by the TAVI operator, including the amount of trauma applied to the conduction system, and medical therapy potentially impairing AV conduction. In the picture, an Allegra transcatheter heart valve is shown (NVT GmbH, Hechingen, Germany).

studies performed after TAVI have shown damage to the AV node, the His, and the infra-His system (34). Of note, there is great anatomical inter-individual variability of the atrioventricular bundle. Some patients have a more rightand some a more left-sided atrioventricular bundle. Patients with a more left-sided atrioventricular bundle may be at a much higher risk for the development of high-degree AVB $(7,35)$. As TAVI relies on oversizing to anchor the device within the native annulus and thus applies force to adjacent structures, many experts believe that PPM rates after TAVI will always be higher than the 3.6-7.1\% observed after open heart surgery was carried out in potential TAVI candidates $(9,10,22)$.

Basically, three major factors contribute to periprocedural mechanical trauma to the conduction system. These are (I) the choice of THV size and type, (II) the size of the balloon used for pre- and postdilatation, if any is used, and (III) the implantation technique (aiming to minimize trauma potentially caused to the annulus and the LVOT). One of the most consistently reported predictors for the occurrence of new conduction disorders is depth of prosthesis implantation. A higher implantation of the SAPIEN 3 or the CoreValve (Medtronic Inc., Minneapolis, MN, USA) has been associated with less PPM $(36,37)$, but this may not be true for all THVs. Indeed, the ACURATE neo (Boston Scientific, Marlborough, MA, USA) may exhibit a lower radial force at the level of the LVOT and thus, it appears that implantation depth may not predict new PPM with this prosthesis (32). This may also explain the overall lower rate of PPM after implantation of the ACURATE neo $(11,32,38,39)$. Furthermore, overexpansion of the LVOT by dilatation with a large balloon or implantation of an oversized prosthesis may increase the risk for conduction disorders and need for a PPM $(25,40)$. Therefore, it is advisable to either omit predilatation or use a balloon that can be accommodated by the LVOT without overstretching the tissue.

Finally, the choice of THV plays a major role. Although there is a great amount of variability regarding the reported proportions of patients requiring implantation of a new PPM with a specific THV, it is clear that some THV such as the Lotus (Boston Scientific) have been associated with high rates of new PPM, whereas the ACURATE neo or more recently the Centera (Edwards Lifesciences) have 
been associated with much lower PPM rates $(12,41)$.

\section{Relevance of medical therapy}

There are numerous articles discussing mechanical trauma to the conduction system, but, to our knowledge, there is no evidence on how to manage medical therapy that has the potential to impair AV conduction in patients undergoing TAVI. However, we feel that this is of importance when we aim to achieve very low pacemaker rates. Negative dromotropic medication such as betablockers, nondihydropyridine calcium channel blockers (verapamil), digoxin, or amiodarone should be stopped 1-2 days before TAVI. They should only be resumed once the ECG of the patient remains stable. In case the patient has atrial fibrillation with a fast ventricular conduction, this usually indicates preserved AV conduction. In such patients, it may be safe to restart negative dromotropic medication earlier after TAVI.

\section{Summary}

The need for a PPM remains an important and frequent problem of TAVI. There are two factors that have the potential for optimization: the amount of trauma caused to the conduction system, and periprocedural management of medical therapy affecting AV conduction. By optimizing these factors, we might finally be able to achieve a very low, surgical-like, rate of new PPM.

\section{Acknowledgements}

None.

\section{Footnote}

Conflicts of Interest: ST serves as a proctor and consultant to Symetis/Boston Scientific and NVT GmbH and has received an institutional research grant from Boston Scientific. RK has received institutional grant support from Abbott, Biotronik, Biosense Webster, Boston Scientific, and Metronic.

\section{References}

1. Linke A, Wenaweser P, Gerckens U, et al. Treatment of aortic stenosis with a self-expanding transcatheter valve: the International Multi-centre ADVANCE Study. Eur
Heart J 2014;35:2672-84.

2. Popma JJ, Adams DH, Reardon MJ, et al. Transcatheter aortic valve replacement using a self-expanding bioprosthesis in patients with severe aortic stenosis at extreme risk for surgery. J Am Coll Cardiol 2014;63:1972-81.

3. Urena M, Rodés-Cabau J. Permanent pacemaker implantation following transcatheter aortic valve replacement: still a concern? JACC Cardiovasc Interv 2015;8:70-3.

4. Toggweiler S, Stortecky S, Holy E, et al. The Electrocardiogram After Transcatheter Aortic Valve Replacement Determines the Risk for Post-Procedural High-Degree AV Block and the Need for Telemetry Monitoring. JACC Cardiovasc Interv 2016;9:1269-76.

5. Elder DH, Lang CC, Choy AM. Pacing-induced heart disease: understanding the pathophysiology and improving outcomes. Expert Rev Cardiovasc Ther 2011;9:877-86.

6. Wilkoff BL, Cook JR, Epstein AE, et al. Dual-chamber pacing or ventricular backup pacing in patients with an implantable defibrillator: the Dual Chamber and VVI Implantable Defibrillator (DAVID) Trial. JAMA 2002;288:3115-23.

7. Auffret V, Puri R, Urena M, et al. Conduction Disturbances After Transcatheter Aortic Valve Replacement: Current Status and Future Perspectives. Circulation 2017;136:1049-69.

8. Kodali S, Thourani VH, White J, et al. Early clinical and echocardiographic outcomes after SAPIEN 3 transcatheter aortic valve replacement in inoperable, high-risk and intermediate-risk patients with aortic stenosis. Eur Heart J 2016;37:2252-62.

9. Smith CR, Leon MB, Mack MJ, et al. Transcatheter versus surgical aortic-valve replacement in high-risk patients. $\mathrm{N}$ Engl J Med 2011;364:2187-98.

10. Adams DH, Popma JJ, Reardon MJ, et al. CoreValve Clinical Investigators. Transcatheter aortic-valve replacement with a self-expanding prosthesis. $\mathrm{N}$ Engl J Med 2014;370:1790-8.

11. Möllmann H, Hengstenberg C, Hilker M, et al. Realworld experience using the ACURATE neo prosthesis: 30-day outcomes of 1,000 patients enrolled in the SAVI TF registry. EuroIntervention 2018;13:e1764-70.

12. Kim U, Blanke P, Windecker S, et al. Computed Tomography-based Oversizing and Incidence of ParaValvular Aortic Regurgitation and Permanent Pacemaker Implantation with a New Generation Self-expanding Transcatheter Heart Valve. EuroIntervention 2018. [Epub 
ahead of print].

13. Leon MB, Smith CR, Mack M, et al. Transcatheter aortic-valve implantation for aortic stenosis in patients who cannot undergo surgery. N Engl J Med 2010;363:1597-607.

14. Meredith IT, Walters DL, Dumonteil N, et al. 1-Year Outcomes With the Fully Repositionable and Retrievable Lotus Transcatheter Aortic Replacement Valve in 120 High-Risk Surgical Patients With Severe Aortic Stenosis: Results of the REPRISE II Study. JACC Cardiovasc Interv 2016;9:376-84.

15. Schymik G, Lefèvre T, Bartorelli AL, et al. European experience with the second-generation Edwards SAPIEN $\mathrm{XT}$ transcatheter heart valve in patients with severe aortic stenosis: 1-year outcomes from the SOURCE XT Registry. JACC Cardiovasc Interv 2015;8:657-69.

16. Möllmann H, Linke A, Holzhey DM, et al. Implantation and 30-Day Follow-Up on All 4 Valve Sizes Within the Portico Transcatheter Aortic Bioprosthetic Family. JACC Cardiovasc Interv 2017;10:1538-47.

17. Popma JJ, Reardon MJ, Khabbaz K, et al. Early Clinical Outcomes After Transcatheter Aortic Valve Replacement Using a Novel Self-Expanding Bioprosthesis in Patients With Severe Aortic Stenosis Who Are Suboptimal for Surgery: Results of the Evolut R U.S. Study. JACC Cardiovasc Interv 2017;10:268-75.

18. Meredith IT, Worthley SG, Whitbourn RJ, et al. Transfemoral aortic valve replacement with the repositionable Lotus Valve System in high surgical risk patients: the REPRISE I study. EuroIntervention 2014;9:1264-70.

19. Binder RK, Rodés-Cabau J, Wood DA, et al. Transcatheter aortic valve replacement with the SAPIEN 3: a new balloon-expandable transcatheter heart valve. JACC Cardiovasc Interv 2013;6:293-300.

20. Wendler O, Schymik G, Treede H, et al. SOURCE 3 Registry: Design and 30-Day Results of the European Postapproval Registry of the Latest Generation of the SAPIEN 3 Transcatheter Heart Valve. Circulation 2017;135:1123-32.

21. Pilgrim T, Stortecky S, Nietlispach F, et al. Repositionable Versus Balloon-Expandable Devices for Transcatheter Aortic Valve Implantation in Patients With Aortic Stenosis. J Am Heart Assoc 2016;5 . pii: e004088.

22. Leon MB, Smith CR, Mack MJ, et al. Transcatheter or Surgical Aortic-Valve Replacement in Intermediate-Risk Patients. N Engl J Med 2016;374:1609-20.

23. Toggweiler S, Humphries KH, Lee M, et al. 5-year outcome after transcatheter aortic valve implantation. J Am Coll Cardiol 2013;61:413-9.

24. Regueiro A, Abdul-Jawad Altisent O, Del Trigo M, et al. Impact of New-Onset Left Bundle Branch Block and Periprocedural Permanent Pacemaker Implantation on Clinical Outcomes in Patients Undergoing Transcatheter Aortic Valve Replacement: A Systematic Review and MetaAnalysis. Circ Cardiovasc Interv 2016;9:e003635.

25. Nazif TM, Dizon JM, Hahn RT, et al. Predictors and clinical outcomes of permanent pacemaker implantation after transcatheter aortic valve replacement: the PARTNER (Placement of AoRtic TraNscathetER Valves) trial and registry. JACC Cardiovasc Interv 2015;8:60-9.

26. Buellesfeld L, Stortecky S, Heg D, et al. Impact of permanent pacemaker implantation on clinical outcome among patients undergoing transcatheter aortic valve implantation. J Am Coll Cardiol 2012;60:493-501.

27. Engborg J, Riechel-Sarup C, Gerke O, et al. Effect of permanent pacemaker on mortality after transcatheter aortic valve replacement. Scand Cardiovasc J 2017;51:40-6.

28. Zhang ZM, Rautaharju PM, Soliman EZ, et al. Mortality risk associated with bundle branch blocks and related repolarization abnormalities (from the Women's Health Initiative [WHI]). Am J Cardiol 2012;110:1489-95.

29. Auffret V, Webb JG, Eltchaninoff H, et al. Clinical Impact of Baseline Right Bundle Branch Block in Patients Undergoing Transcatheter Aortic Valve Replacement. JACC Cardiovasc Interv 2017;10:1564-74.

30. van der Boon RM, Van Mieghem NM, Theuns DA, et al. Pacemaker dependency after transcatheter aortic valve implantation with the self-expanding Medtronic CoreValve System. Int J Cardiol 2013;168:1269-73.

31. Boerlage-Van Dijk K, Kooiman KM, Yong ZY, et al. Predictors and permanency of cardiac conduction disorders and necessity of pacing after transcatheter aortic valve implantation. Pacing Clin Electrophysiol 2014;37:1520-9.

32. Toggweiler S, Nissen H, Mogensen B, et al. Very low pacemaker rate following ACURATE neo transcatheter heart valve implantation. EuroIntervention 2017;13:1273-80.

33. Tzamtzis S, Viquerat J, Yap J, et al. Numerical analysis of the radial force produced by the Medtronic-CoreValve and Edwards-SAPIEN after transcatheter aortic valve implantation (TAVI). Med Eng Phys 2013;35:125-30.

34. Rubín JM, Avanzas P, del Valle R, et al. Atrioventricular conduction disturbance characterization in transcatheter aortic valve implantation with the CoreValve prosthesis. 
Circ Cardiovasc Interv 2011;4:280-6.

35. Kawashima T, Sato F. Visualizing anatomical evidences on atrioventricular conduction system for TAVI. Int J Cardiol 2014;174:1-6.

36. Husser O, Pellegrini C, Kessler T, et al. Predictors of Permanent Pacemaker Implantations and New-Onset Conduction Abnormalities With the SAPIEN 3 BalloonExpandable Transcatheter Heart Valve. JACC Cardiovasc Interv 2016;9:244-54.

37. Muñoz-García AJ, Hernández-García JM, JiménezNavarro MF, et al. Factors predicting and having an impact on the need for a permanent pacemaker after CoreValve prosthesis implantation using the new Accutrak delivery catheter system. JACC Cardiovasc Interv 2012;5:533-9.

Cite this article as: Toggweiler S, Kobza R. Pacemaker implantation after transcatheter aortic valve: why is this still happening? J Thorac Dis 2018;10(Suppl 30):S3614-S3619. doi:10.21037/jtd.2018.06.103
38. Maeno Y, Abramowitz Y, Kawamori H, et al. A Highly Predictive Risk Model for Pacemaker Implantation After TAVR. JACC Cardiovasc Imaging 2017;10:1139-47.

39. Kapadia SR, Wazni O, Krishnaswamy A. Pacemaker Implantation After TAVR. JACC Cardiovasc Imaging 2017;10:1148-50.

40. Maan A, Refaat MM, Heist EK, et al. Incidence and Predictors of Pacemaker Implantation in Patients Undergoing Transcatheter Aortic Valve Replacement. Pacing Clin Electrophysiol 2015;38:878-86.

41. van Rosendael PJ, Delgado V, Bax JJ. Pacemaker implantation rate after transcatheter aortic valve implantation with early and new-generation devices: a systematic review. Eur Heart J 2018;39:2003-13. 